Boise State University

ScholarWorks

Counselor Education Faculty Publications and

Presentations

Department of Counselor Education

$1-1-2012$

Daytime Predictors of Evening Alcohol Use: Treatment Implications for Moderate to Heavy Drinkers

Diana M. Doumas

Boise State University 
This is an electronic version of an article published in Alcoholism Treatment Quarterly, Jan-Mar 2012, Volume 30, Issue 1, 78-90. Alcoholism Treatment Quarterly is available online at: www.tandfonline.com.

\title{
Daytime Predictors of Evening Alcohol Use: Treatment Implications for Moderate to Heavy Drinkers
}

\author{
Diana M. Doumas, PhD \\ Boise State University
}

\begin{abstract}
This study examined daytime mood, stress, and drinking-related consequences as predictors of evening alcohol use. Twenty-four moderate to heavy drinkers completed diaries twice daily for 28 days. Results of hierarchical linear modeling (HLM) analyses indicated daytime negative mood states predicted higher levels of evening alcohol use, whereas negative drinking-related consequences predicted lower levels of subsequent alcohol use. Clinical implications include emphasizing negative drinking-related consequences in enhancing client motivation to change. Results also support routine assessment of anxiety and depressed mood to help clinicians identify risk factors for drinking and provide intervention strategies targeting negative mood states to improve treatment outcomes.
\end{abstract}

Keywords: alcohol use, diary study, moderate to heavy drinkers

The individual and societal costs associated with alcohol abuse and dependence are well documented. National survey data indicate that $30 \%$ of the general population drinks at levels that put them at risk for alcoholism (National Institute of Alcoholism and Alcohol Abuse, 2010). Despite the prevalence of problematic substance use, enrollment in alcohol and drug treatment programs is rare. In fact, over $94 \%$ of those suffering from chemical dependency do not think they need treatment, and as a result, do not seek treatment (U.S. Department of Health and Human Services, 2003). Further, although the majority of intervention research targets chronic or heavy drinkers, moderate and heavy drinkers may also be at risk for problems associated with their drinking (Meyerhoff, Bode, Nixon, deBruin, Bode, \& Seitz, 2005; Walitzer \& Colins, 1999), even though they may not meet criteria for alcohol abuse or dependence. Therefore, it is important to understand factors that contribute to alcohol use in this group of drinkers in order to provide treatment strategies tailored for these individuals.

The etiology of alcohol use is both complex and multidimensional (Cooper, Frone, Russell, \& Mudar, 1995). Researchers have developed models of alcohol use such as the tension-reduction model (Greely \& Oei, 1999) and stress-dampening model (Sher, 1987) that suggest individuals drink to reduce stress or alleviate anxiety. Drinking motives, such as drinking to cope with negative affect and drinking to enhance or maintain positive experiences, have also been identified as motivators for drinking (Cooper, et al., 1995). Similarly, the stressor-vulnerability model combines drinking motives, coping skills, and situational variables, suggesting individuals with strong beliefs regarding alcohol's ability to reduce tension or increase positive experiences, coupled with limited coping resources, are more likely to respond to stressful situations by drinking (e.g., Cooper, Russell, \& George, 1988).

Consequences of drinking are also thought to influence subsequent decisions to drink (Young \& Oei, 1993). Although the mechanism by which drinking-related consequences are associated with alcohol use are not well understood, it is a common practice to discuss negative consequences of alcohol use as a strategy to increase client awareness of the risks associated with their behavior to help motivate clients to change (Miller \& Rollnick, 2002). In contrast to the well-developed theories concerning antecedents and motivations for drinking, comprehensive theories regarding the relationship of drinking-related consequences to subsequent drinking are not as well-defined. For example, although drinking-related consequences are associated with alcohol use, this relationship is not consistent and may be better explained by alcohol-related beliefs (Turrisi, Wiersma, \& Hughes, 2000).

Although most studies examining antecedents and consequences of alcohol use have used retrospective assessments of these variables, these designs are limited in assessing the temporal relationships between antecedents and shortterm consequences of alcohol consumption. Over the past decade, researchers have moved away from crosssectional, between-persons designs to study within-person variability using daily diary methodology. Researchers examining diary methods in relation to other methods has identified advantages of daily reporting over crosssectional retrospective methods, including a reduction in memory distortions that occur with retrospective data, 
This is an electronic version of an article published in Alcoholism Treatment Quarterly, Jan-Mar 2012, Volume 30, Issue 1, 78-90. Alcoholism Treatment Quarterly is available online at: www.tandfonline.com.

DOI: 10.1080/07347324.2012.635527

allowing for the examination of the within-person variability in the studied relationships, and identifying temporal relationships among variables (Armeli, Todd, \& Mohr, 2005; Carney, Tennen, Affleck, Del Boca, \& Kranzler, 1998; Mohr, Armeli, Tennen, \& Todd, 2010; Searles, Helzer, Rose, \& Badger, 2002),.

A growing body of research has used daily diary designs to better understand the antecedents of alcohol use by examining within-person variability. These investigations support the stress-dampening and stressor-vulnerability models, demonstrating a relationship between alcohol consumption and both positive and negative daily events (Armeli, Tennen, Affleck, \& Kranzler, 2000; Armeli, Tennen, Todd, Carney, Mohr, Affleck et al., 2003; Carney, Armeli, Tennen, Affleck, \& O’Neil, 2000) and stress (Armeli, Carney, Tennen, Affleck, \& O’Neil, 2000; Armeli, Dehart, Tennen, Todd, Affleck, 2007; Mohr, Armeli, Tennen, Carney, Affleck, \& Hromi, 2001). Daily diary research has also demonstrated a relationship between alcohol use and negative mood (Armeli et al., 2003; Armeli, et al., 2007; Swendsen, Tennen, Carney, Affleck, Willard, \& Hromi, 2000), supporting drinking to cope, or selfmedication, as a motivator of alcohol use. In addition, research suggests the relationship between alcohol use and stressful events and negative mood states may be particularly pronounced for males (Armeli et al., 2000; Carney et al., 2000; Swendsen et al., 2000), indicating gender differences in the impact of predictor variables on alcohol use.

While the diary methodology used in these studies allows for the examination of within-person variability, limitations still exist in the identification of temporal and causal relationships due to the common use of nightly diary reports of events that occur throughout the day. A few studies have addressed this issue by using repeateddaily measurements, hand held computers, and in vivo reporting of mood and alcohol consumption to establish temporal ordering of variables (Armeli et al., 2003; Armeli et al., 2007; Mohr et al., 2001; Swendsen et al., 2000) but most included other reporting components that limited temporal conclusions regarding some of the studied relationships. Further, diary studies that have examined alcohol use have been primarily concerned with understanding the motivations and antecedents related to alcohol consumption within the framework of the stressdampening model (e.g., Armeli et al., 2003), the stressor-vulnerability model (e.g., Armeli et al., 2000), and the selfmedication hypothesis (e.g., Swendsen et al., 2000). Missing from the literature, however, is a daily examination of the consequences of alcohol use and the impact of drinking-related consequences on subsequent alcohol use.

The aim of the current study is to take a first step in bridging this gap by examining the effect of daytime mood, stress, and drinking-related consequences on evening alcohol use using daily diary methodology. This study expands upon the literature by 1) examining the relationship of drinking-related consequences on subsequent alcohol consumption in addition to examining mood and stress as antecedents of alcohol use, and 2) collecting two daily reports to isolate daytime mood, stress, and drinking-related consequences temporally from evening reports of alcohol consumption. Further, as previous research has indicated relationships between daily events and drinking vary as a function of gender (Armeli et al., 2000; Carney et al., 2000), gender was examined as a moderator of the relationship between daytime mood, stress, and drinking-related consequences and evening alcohol use.

The following hypotheses were examined in the current study. First, based on research indicating a positive relationship between stress (Armeli et al., 2000; Armeli et al., 2007; Moh et al., 2001) and negative mood states (Armeli et al., 2003; Armeli, et al., 2007; Swendsen et al., 2000) and alcohol use it was hypothesized that reports of stress and negative mood states would be associated with subsequent alcohol consumption. The analyses for alcohol-related consequences are considered exploratory as consequences could be associated with subsequent increases in alcohol-consumption ("hair of the dog") or subsequent decreases in consumption ("I'll never drink again). Finally, based on research suggesting the relationship of stress and mood to alcohol use may be stronger for males (Armeli et al., 2000; Carney et al., 2000; Swendsen et al., 2000), we hypothesized we would find similar gender differences.

\section{Method}

\section{Participants and Procedures}

Community residents, ages 21-50, were recruited from a metropolitan area in the rocky mountain region in 2005 and 2006. Participants were recruited through the use of newspaper and radio advertisements for a study on drinking. Individuals who respond to the advertisement were selected based on telephone screening criteria. Individuals were screened on level of alcohol use, with the goal of selecting moderate to heavy drinkers who were not alcohol dependent. Moderate to heavy drinkers were defined by the consumption quantities outlined by Sanchez-Craig, 
This is an electronic version of an article published in Alcoholism Treatment Quarterly, Jan-Mar 2012, Volume 30, Issue 1, 78-90. Alcoholism Treatment Quarterly is available online at: www.tandfonline.com.

DOI: 10.1080/07347324.2012.635527

Wilkinson, and Davila (1995). Women reporting drinking at least 12 standard drinks per week and men reporting drinking at least 16 standard drinks per week, with at least 12 drinking days per month were considered moderate to heavy drinkers. Individuals were also screened for potential alcohol dependence using the CAGE Inventory (Mayfield, McLeod, \& Hall, 1974; Hays, Merz, \& Nicholas, 1995). These criteria were selected on the basis of previous studies and were intended to produce a sample of participants who had high enough levels of drinking to allow for the assessment of relationships between drinking and other variables during the diary period.

In eight months of active recruitment, 207 individuals responded to the advertisements. Of these 207, approximately $50 \%$ did not respond to the contact after their initial call. Of the 104 that were screened for the study, 30\% were excluded for low levels of drinking, 37\% were excluded for potential alcohol dependence (CAGE score), and 10\% did not meet the age criteria. The final sample consisted of 24 participants (53\% male, 47\% female). Participant ages ranged from 21 to $47(M=29.92, S D=7.55)$. Participants were primarily Caucasian $(96 \%)$. Seventy-five percent of participants were single, $21 \%$ married, and $4 \%$ divorced. Years of education ranged from 10-20 years ( $M$ $=14.69, S D=2.46)$ and annual income ranged from $\$ 1,040-\$ 82,000(M=\$ 24,860, S D=\$ 17.727)$. Participants were primarily employed, with $70 \%$ employed full-time, $17 \%$ employed part-time, and $13 \%$ unemployed.

Participants who met criteria for the study were invited to attend a 30-minute interview during which they were trained to complete the daily diaries. All participants were treated according to established APA ethical standards, completed informed consent, and the University Institutional Review Board approved all research procedures. Participants were paid \$15 for their participation in this session and an additional \$60 when they completed the 28 days of diary data. Participants were instructed to complete the questionnaires twice a day, at $4 \mathrm{pm}$ and before bedtime. Directions included that when they complete the questionnaire at $4 \mathrm{pm}$, they were to report on the time between waking up and $4 \mathrm{pm}$ and for the questionnaire at bedtime, they were to report on the time between $4 \mathrm{pm}$ and bedtime. This was true for all items on the diary. They were instructed to mail the questionnaires the next day in postage-paid return envelopes. Participants were provided with questionnaires and stamped envelopes for 4 weeks.

Participants were also paid an additional \$20 for perfect reporting which was defined as 1) postmarks indicating the questionnaires were mailed the day after reporting, and 2) less than 6 errors or instances of missing data. The bonus was given to minimize errors and encourage same-day reporting. Participants were called immediately if their questionnaire was late or if there was any missing data. The phone call served to troubleshoot any problems the participant was experiencing in completing the diary, provide encouragement, and collect missing data. On $80 \%$ of the days, postmarks indicated that participants filled out the diaries on the correct day, and more than $99 \%$ of the questionnaires were filled out within 48 hours. All daily questionnaires were eventually completed by $100 \%$ of the participants.

\section{Measures}

The Daily Diary included reports in the following areas: alcohol consumption, mood, stress, and drinking-related consequences.

Alcohol Consumption. Participants recorded the number of drinks consumed, and size of drinks in ounces in three categories: beer, wine, and liquor. For each category, standard measurements were listed as follows: beer (12 oz, 4$5 \%$ alcohol); hard liquor (1.25 oz of 80 proof, $1 \mathrm{oz} 100$ proof); wine (4 oz, 12.5\% alcohol). These entries were later converted into the number of standard drinks consumed.

Mood. Anxious and depressed mood states were assessed using items from the Profile of Mood States (Lorr \& McNair, 1971). Items are rated on a 5-point scale from not at all to extremely. Items were selected using the procedure employed by Thompson \& Bolger (1999) in which the four highest loading items from a factor analysis conducted by Lorr and McNair were used to measure each mood state. The items that were used to measure anxiety were "on edge", "uneasy", "anxious", and "nervous". The items that were used to measure depression were "hopeless", "worthless", "sad", and "discouraged". The range of possible scores was $1-40$. Alphas for anxiety and depression were reported at .86 and .78, respectively. In this study, the alpha for the 8-item negative mood states scale was .94.

Perceived Stress. Perceived stress was assessed using a modified version of the 4-item Perceived Stress Scale (PSS; Cohen, Kamarck, \& Mermelstein, 1983). The original list refers to symptoms experienced in the last month, 
therefore modifications were made to assess for daily symptoms. The PSS has demonstrated internal consistency with alpha coefficients ranging from .73 to .88 (Carney et al., 2000; Todd et al., 2003). This scale has been employed as a measure of daily stress in a variety of prior research projects. The range of possible scores was $1-$ 16. In this study, the alpha for the 4-item scale was .93.

Drinking-Related Consequences. Behavioral and interpersonal consequences were assessed using a modified version of the Young Adult Alcohol Problems Screening Test (YAAPST; Hulburt \& Sher, 1992). Test-retest reliability of this measure is reported at .73. Questions were modified to assess daily rather than global consequences. Five items were used to create a drinking-specific consequences scale including vocational, physical, and interpersonal consequences of drinking. These items were: "You showed up late for work or did not go to work because of drinking, a hangover, or an illness caused by drinking; Your drinking created problems between you and your boyfriend/girlfriend (or spouse), friend or another near relative; You neglected your obligations, your family or your work because of your drinking; You had a headache (hangover), felt sick or threw up because of your drinking; You got into fights, acted bad, or did mean things because of your drinking.” The range of possible scores was 1 5. The alpha for the 5-point scale was .72.

\section{Data Analysis Strategy}

Hierarchical linear modeling (HLM) was used to examine the effect of daily daytime mood, stress, and drinkingrelated consequences on evening alcohol consumption. HLM was selected as this analysis strategy allows for the testing of within-person (Level 1) and between-person (Level 2) relationships. In HLM, regression equations are estimated for the within-person and between-person models. To examine the impact of daily variables on evening alcohol use, the following Level 1 fixed effect model was fit:

$$
\text { Alcohol }_{i t}=b_{0 i}+b_{1 i}\left(\text { Mood }_{i t}\right)+b_{2 i}\left(\text { Stress }_{i t}\right)+b_{3 i}\left(\text { Consequences }_{i t}\right)+e_{i t}
$$

where Alcohol $_{i t}$ is the evening alcohol use of person $\mathrm{i}$ on day $\mathrm{t}$; $\mathrm{b}_{01}$ is the intercept for person $\mathrm{i}$ (the predicted value of evening alcohol use when all of the predictors equal 0 ); $b_{1 i}, b_{2 i}$, and $b_{3 i}$ are the partial slopes for the associations between evening alcohol use and daytime mood, stress, and drinking-related consequences; and $\mathrm{e}_{i t}$ a random residual component. All of the Level 1 predictors were centered within-person, thus, $b_{0 \mathrm{i}}$ in the above equation can be interpreted as the average level of alcohol consumption adjusted for individual differences in mood, stress, and drinking-related consequences.

To assess the moderating effects of gender on the within-person relations (Level 1 slopes), Level 1 parameters (intercepts and slopes) were regressed on the between-person (Level 2) predictor, gender. The following equation shows the Level 2 model predicting the Level 1 within-person association between daily predictors and drinking:

$$
\mathrm{b}_{1 \mathrm{i}}(\operatorname{mood})=\mathrm{y}_{10}+\mathrm{y}_{11}\left(\text { Gender }_{\mathrm{i}}\right)+\mathrm{u}_{1 \mathrm{i}}
$$

where the Level 1 parameter $\left(b_{1 i}\right)$ is modeled as a function of gender and a random-person effect $\mathrm{u}_{11}$. The Level 2 predictors were grand mean centered, so $\mathrm{y}_{10}$ can be interpreted as the average within-person relationship between daily predictors and evening drinking and $\mathrm{y}_{11}$ can be interpreted as the difference between men and women in the daily predictors to evening drinking relationship.

\section{Results}

\section{Descriptive Statistics}

Means, standard deviations, and correlations for the between-person variables are reported in Table 1. The means represent the daily mean of each variable across participants. A series of independent sample t-tests indicated there were no gender differences in stress, mood, or drinking-specific consequences. There was, however, a statistical trend toward a gender difference in weekly drinking, $t(1,23)=2.01, p=.06$, Cohen's $d=.84$, with males $(M=1.86$, $S D=1.30)$ reporting consuming more drinks per day than females $(M=1.04, S D=0.48)$. The correlation between stress and mood was significant and strong, whereas the correlations among the other predictor variables were in the medium range, although not significant. 
This is an electronic version of an article published in Alcoholism Treatment Quarterly, Jan-Mar 2012, Volume 30, Issue 1, 78-90. Alcoholism Treatment Quarterly is available online at: www.tandfonline.com.

DOI: 10.1080/07347324.2012.635527

\section{Multilevel Regression Analyses}

Daytime stress, mood, and drinking-related consequences were entered simultaneously into the fixed effects model. The overall chi-square indicated good model fit $\left(\chi^{2}=284.04, \mathrm{p}<.001\right)$. The variance for the Level 1 analysis was 8.04, $\left(\chi^{2}=249.14, \mathrm{p}<.001\right)$. As seen in Table 2, daytime mood states and drinking-related consequences were uniquely related to evening alcohol use. Examination of the direction of the beta weights indicated a positive relationship between daytime mood states and evening alcohol use and an inverse relationship between drinkingrelated consequences and evening alcohol use. That is, high levels of anxiety and depression during the daytime predicted high levels of evening alcohol consumption, whereas high levels of drinking-specific consequences during the daytime predicted low levels of alcohol consumption. Daytime stress, however, was not a significant predictor of evening alcohol use.

Next we examined gender as a moderator of the relationship between daily predictors and evening drinking by testing whether any of the unique within-person relationships varied as a function of gender. Results of the Level 2 model indicated gender was not a significant predictor in the model (see Table 2), indicating the relationship between the daily predictors and evening alcohol consumption did not vary as a function of gender.

\section{Discussion}

This study examined daytime mood, stress, and drinking-related consequences as predictors of evening alcohol in a sample of moderate to heavy drinkers. Participants completed daily diaries two times a day across 28 days. Results indicated daytime mood and drinking-related consequences were unique predictors of evening alcohol use. Specifically, anxious and depressed mood were positively related to evening alcohol consumption, whereas drinking-related consequences were inversely related to evening alcohol consumption. Daytime stress, however, was not a significant predictor or evening alcohol use. Because diaries were completed two times per day, results of this study also indicate a temporal relationship between mood, drinking-related consequences, and alcohol consumption. Findings suggest that evening alcohol use is impacted by negative mood states occurring earlier in the day and negative drinking-related consequences experienced earlier in the day decrease subsequent alcohol use.

Results of this study are consistent with the drinking to cope with negative affect model (Copper et al., 1995). The relationship between the daytime negative mood states of depression and anxiety and evening alcohol use supports the use of alcohol as a way to cope with negative mood states and is consistent with diary studies examining the relationship between mood and alcohol use (Armeli et al., 2003; Armeli et al., 2007; Swendsen et al., 2000). In contrast, results were not consistent with the stress-dampening model (Sheri, 1987), as daytime stress was not a significant predictor of evening alcohol use. Although other diary studies have demonstrated a relationship between stress and alcohol use (Armeli, Carney, et al., 2000; Mohr et al., 2001), the majority of these studies examined positive and negative events as indicators of stress, rather than perceived stress (Armeli, Tennen, et al., 2000; Armeli et al., 2003; Carney et al., 2000). In addition, in the present study, mood and stress were examined simultaneously, possibly leading to the difference in results between studies.

This study also demonstrates the importance of negative drinking-related consequences as experiences that may serve to motivate individuals to reduce subsequent drinking. To date, this is the first diary study to examine drinking-related consequences as a predictor of subsequent alcohol consumption. Results indicate that reports of drinking-specific consequences from the previous evening's drinking predicted lower levels alcohol use the next evening. This suggests that decisions to drink may be impacted by the experience of negative consequences associated with drinking the prior evening. Thus, in this group of moderate to heavy drinkers, experiencing negative consequences reduced subsequent drinking. This finding is particularly important as it distinguishes this group of drinkers from drinkers who consume alcohol despite the experience of negative consequences and may be more likely to meet criteria for alcohol abuse or dependence.

Gender differences in the relationship between daytime predictors and evening drinking were also examined. Although, on average, men in this study drank more than women, there were no gender differences in the daily relationships between daytime predictors and evening alcohol use. Although these findings are inconsistent with previous studies indicating these patterns are more prevalent in men (Armeli et al., 2000; Carney et al., 2000), this discrepancy may be due, in part, to what types of predictor variables were included in the study. For example, both Armeli et al. and Carney et al. examined stressful events in particular, whereas the present study assessed perceived 
This is an electronic version of an article published in Alcoholism Treatment Quarterly, Jan-Mar 2012, Volume 30, Issue 1, 78-90. Alcoholism Treatment Quarterly is available online at: www.tandfonline.com.

DOI: 10.1080/07347324.2012.635527

stress, mood states and drinking-related consequences simultaneously as predictors of evening alcohol use. In addition, in the present study, diaries were completed two times per day, whereas in both the Armeli et al. and Carney et al. studies, diaries were completed only in the evening.

Although this study provides an initial step toward extending the literature on the relationship between daytime predictors of evening alcohol use among moderate to heavy drinkers, several limitations deserve note. First, the small sample size limits the generalizability of this study. Although 207 individuals responded to the advertisements, only 104 responded to the contact after their initial call. Further, it was difficult to find participants who met the criteria for moderate to heavy drinking. Of the respondents screened, $30 \%$ were excluded for low levels of drinking and 37\% were excluded for high levels of drinking. Thus, despite active recruitment for 8 months, we were only able to acquire a study sample of 24 moderate to heavy drinkers. Future research with larger samples is needed to replicate the results of this study. Additionally, data were collected through self-report diaries. And, even though participants were asked to complete diaries two times per day, it is possible that participants completed both questionnaires in the evening. The use of addiction incentives for "perfect reporting" likely increased timely survey completion, but may not have impacted adherence to completing the survey at two time points during the day. Future research should make use of technological advances, such as hand held computers, electronic diaries, or texting to capture data throughout the day and use this technology to measure temporal relationships among daily variables.

Despite these limitations, this study has important implications for developing early intervention strategies for moderate to heavy drinkers who do not yet meet criteria for alcohol dependence. Although research indicates that brief interventions are effective in reducing alcohol use (Miller, Wilbourne, \& Hettema, 2003), most problem drinkers do not seek treatment (Cunningham \& Breslin, 2004). In response to this problem, brief online interventions have been developed as research indicates these interventions are both attractive to moderate drinkers (Koski-Janne \& Cunningham, 2001) and effective in reducing heavy drinking in the general population (Vernon, 2010). Results of this study suggest motivational enhancement techniques, whether delivered in-person or online, may be particularly useful with moderate to heavy drinkers. Specifically, motivational enhancement models emphasize the impact of drinking-related consequences and the discrepancy between one's current drinking and future goals to promote motivation to change (see Miller \& Rollnick, 2002). Results of this study support highlighting negative drinking-related consequences as a strategy to reduce subsequent alcohol use.

Findings from this study also indicate that experiencing depressed or anxious mood states during the day were associated with an increase in alcohol use in the evening. These results point to the importance of addressing negative mood states as part of alcohol treatment, adding to prior research indicating negative emotional states are the leading relapse trigger for alcohol abuse (Hodgins, el-Guebaly, \& Armstrong, 1995; Sandberg \& Marlatt, 1991) and high levels of depression and anxiety at alcohol treatment entry are significant risk factors for treatment attrition (Doumas, Blasey, \& Thacker, 2005). Despite the impact of depressed and anxious mood on alcohol use and treatment outcomes, routine assessment of depression and anxiety are not included in the assessment of clients presenting with substance-related issues. Findings from this study highlight the importance of including mood assessment as part of an initial therapy session with moderate to heavy drinkers and providing intervention strategies targeting depression and anxiety as part of treatment. These interventions may include adjunctive group or individual treatment providing cognitive-behavioral therapy for depression and anxiety to target these mood symptoms. 
This is an electronic version of an article published in Alcoholism Treatment Quarterly, Jan-Mar 2012, Volume 30, Issue 1, 78-90. Alcoholism Treatment Quarterly is available online at: www.tandfonline.com.

DOI: 10.1080/07347324.2012.635527

\section{References}

Armeli, S., Carney, M. A., Tennen, H., Affleck, G., \& O’Neil, T. (2000). Stress and alcohol use: A daily process examination of the stressor-vulnerability model. Journal of Personality and Social Psychology, 78, 979994.

Armeli, S., Dehart, T., Tennen, H., Todd, M., \& Affleck, G. (2007). Daily interpersonal stress and the stressor-vulnerability model of alcohol use. Journal of Social and Clinical Psychology, 26, 896-921.

Armeli, S., Tennen, H., Affleck, G., \& Kranzler, H. R. (2000). Does affect mediate the association between daily events and alcohol use. Journal of Studies on Alcohol, 61, 862-871.

Armeli, S., Tennen, H., Todd, M., Carney, M. A., Mohr, C., Affleck, G., \& Hromi, A. (2003). A daily process examination of the stress-response dampening effects of alcohol consumption. Psychology of Addictive Behaviors, 17, 266-276.

Armeli, S., Todd, M., \& Mohr, C. (2005). A daily process approach to individual differences in stress-related alcohol use. Journal of Personality, 73(6), 1-30..

Carney, M.A., Armeli, S., Tennen, H., Affleck, G., \& O’Neil, T. P. (2000). Positive and negative daily events, perceived stress, and alcohol use: A diary study. Journal of Consulting and Clinical Psychology, 68, 788798.

Carney, M.A., Tennen, H, Affleck, G., del Boca, F. K., \& Kranzler, H. R. (1998). Levels and patterns of alcohol consumption using timeline follow-back, daily diaries and real-time "electronic interviews". Journal of Studies on Alcohol, 59, 447-454.

Cohen, S., Kamarck, T., \& Mermelstein, R. (1983). A global measure of perceived stress. Journal of Health and Social Behavior, 24, 385-396.

Cooper, M. L., Frone, M. R., Russell, M., \& Mudar, P. (1995). Drinking to regulate positive and negative emotions: A motivational model of alcohol use. Journal of Personality and Social Psychology, 69, 990-1005.

Cooper, M. L., Russell, M., \& George, W. H. (1988). Coping, expectancies, and alcohol abuse: A test of social learning formulations. Journal of Abnormal Psychology, 97, 218-230.

Cox, W. M., \& Klinger, E. (1988). A motivational model of alcohol use. Journal of Abnormal Psychology, 97, 168180. 
This is an electronic version of an article published in Alcoholism Treatment Quarterly, Jan-Mar 2012, Volume 30, Issue 1, 78-90. Alcoholism Treatment Quarterly is available online at: www.tandfonline.com.

DOI: 10.1080/07347324.2012.635527

Cox, W. M., \& Klinger, E. (1990). Incentive motivation, affective change, and alcohol use: A model. In W. M. Cox (Ed.). Why people drink: Parameters of alcohol as a reinforcer (pp. 291-314). New York, NY: Gardner Press.

Cunningham, J. A., \& Breslin, F. C. (2004). Only one in three people with alcohol abuse or dependency ever seek treatment. Addictive Behavior, 29, 221-223.

Doumas, D. M., Blasey, C. M., \& Thacker, C. (2005). Attrition from alcohol and drug outpatient treatment: Psychological distress and interpersonal problems as indicators. Alcoholism Treatment Quarterly, 23(4), 55-67.

Greeley, J., \& Oei, T. (1999). Alcohol and tension reduction. In K.E. Leonard \& H. T. Blaine (Eds.), Psychological theories of drinking and alcoholism (2 ${ }^{\text {nd }}$ ed., pp. 14-53). New York: Guilford Press.

Hays, R. D., Merz, J. F., \& Nicholas, R. (1995). Response burden, reliability, and validity of the CAGE, Short MAST, and AUDIT alcohol screening measures. Behavior Research Methods, Instruments, and Computers, 27, 277-280.

Hodgins, D. C., el-Guebaly, N., \& Armstrong, S. (1995). Prospective and retrospective reports of mood states before relapse to substance use. Journal of Consulting \& Clinical Psychology, 63, 400-407.

Hurlbut, S. C, \& Sher, K. J. (1992). Assessing alcohol problems in college students. Journal of American College Health, 41, 49-58.

Koski-Janne, A. \& Cunningham, J. (2001). Interest in different forms of self-help in a general population sample of drinkers. Addictive Behavior, 26, 91-99.

Lemmens, P., Knibbe, R. A., \& Tan, F. (1988). Weekly recall and diary estimates of alcohol consumption in a general population survey, Journal of Studies on Alcohol, 49(2), 131-135.

Lorr, M., \& McNair, D. M. (1971). The Profile of Mood States manual. San Diego, CA: Educational and Industrial Testing Service.

Mayfield, D., McLeod, G., \& Hall, P. (1974). The CAGE questionnaire: Validation of a new alcoholism instrument. American Journal of Psychiatry, 131, 1121-1123.

Meyerhoff, D. J., Bode, C., Nixon, S. J., deBruin, E. A., Bode, J. C., Seitz, H. K. (2005). Health risks of chronic moderate and heavy alcohol consumption: How much is too much? 
This is an electronic version of an article published in Alcoholism Treatment Quarterly, Jan-Mar 2012, Volume 30, Issue 1, 78-90. Alcoholism Treatment Quarterly is available online at: www.tandfonline.com. DOI: 10.1080/07347324.2012.635527

Alcoholism: Clinical and Experimental Research, 29, 1334-1340.

Miller, W. R., \& Rollnick, S. (2002). Motivational interviewing: Preparing people to change addictive behavior $\left(2^{\text {nd }}\right.$ Ed). New York, NY: Guilford Press.

Miller, W. R., Wilbourne, P. L., \& Hettema, J. E. (2003). What works? A summary of alcohol treatment outcome research. In R. K. Hester and W. R. Miller (Eds.). Handbook of alcoholism treatment approaches: Effective alternatives ( $3^{\text {rd }}$ ed., pp. 13-63). Boston: Allyn \& Bacon.

Mohr, C. D., Armeli, S., Tennen, H., Carney, M.A., Affleck, G., \& Hromi, A. (2001). Daily interpersonal experiences, context, and alcohol consumption: Crying in your beer and toasting good times. Journal of Personality and Social Psychology, 80, 489-500.

Mohr, C., Armeli, S., Tennen, H., \& Todd, M. (2010). The complexities of modeling mood-drinking relationships: Lessons learned from daily process research. In J. D. Kassel (Ed.). Substance abuse and emotion (pp. 189216). Washington, DC: American Psychological Association.

National Institute of Alcoholism and Alcohol Abuse (2010). Rethinking drinking: Alcohol and your health. http://pubs.niaaa.nih.gov/publications/rethinkingdrinking/rethinking_drinking.pdf

Sanchez-Craig, M., Wilkinson, A., \& Davila, R. (1995). Empirically based guidelines for moderate drinking: 1-year results from three studies with problem drinkers. American Journal of Public Health, 85, 823-828.

Sandberg, G. G., \& Marlatt, G. A. (1991). Relapse prevention. In D.A. Ciraulo. \& R.I. Shader (Eds.), Clinical manual of chemical dependence (pp. 377-399). Washington, DC: American Psychiatric Association.

Searles, J. S., Helzer, J. E. Rose, G. L., \& Badger, G. J. (2002). Concurrent and retrospective reports of alcohol consumption across 30, 90 and 366 days: Interactive voice response compared with the timeline follow back. Journal of Studies on Alcohol, 63, 352-362.

Sher, K. J. (1987). Stress response dampening. In H. T. Blaine \& K. E. Leonard (Eds). Psychological Theories of Drinking and Alcoholism (pp. 227-271). New York: Guilford Press. 
This is an electronic version of an article published in Alcoholism Treatment Quarterly, Jan-Mar 2012, Volume 30, Issue 1, 78-90. Alcoholism Treatment Quarterly is available online at: www.tandfonline.com.

DOI: 10.1080/07347324.2012.635527

Swendsen, J. D., Tennen, H., Carney, M. A., Affleck, G., Willard, A., \& Hromi, A. (2000). Mood and alcohol consumption: An experience sampling test of the self-medication hypothesis. Journal of Abnormal Psychology, 109, 198-204.

Thompson, A., \& Bolger, N. (1999). Emotional transmission in couples under stress. Journal of Marriage and the Family, 61, 38-48.

Turrisi, R., Wiersma, K.A., \& Hughes, K. K. (2000). Binge-drinking-related consequences in college students: role of drinking beliefs and mother-teen communications. Psychology of Addictive Behaviors, 14, 342-355.

U.S. Department of Health and Human Services. (2003). 22 Million in U.S. suffer from substance dependence of abuse. http://www.hhs.gov/news/press/2003pres/20030905.html.

U.S. Department of Human Health and Services (2010). Summary statistics for U.S. adults: National health interview survey, 2009. http://www.cdc.gov/nchs/data/series/sr_10/sr10_249.pdf

Vernon, M. L. (2010). A review of computer-based alcohol problem services designed for the general public. Journal of Substance Abuse Treatment, 38, 203-211.

Walitzer, K. S., \& Colins, G. J. (1999). Treating problem drinkers. Alcohol Research \& Health, 23 (2), $138-143$.

Young, R., \& Oei, T. (1993). Grape expectations: the role of alcohol expectations in the understanding and treatment of problem drinking. International Journal of Psychology, 28, 337-364. 
This is an electronic version of an article published in Alcoholism Treatment Quarterly, Jan-Mar 2012, Volume 30, Issue 1, 78-90. Alcoholism Treatment Quarterly is available online at: www.tandfonline.com.

DOI: 10.1080/07347324.2012.635527

Table 1

Descriptive Statistics and Correlations

Variable

1. Drinks

3. Stress

4. Consequences
2. Mood
Mean

1.51

11.50

3.39

0.11

0.14
$0-19$

$8-32$

$0-16$

$0-5$
2

3

$* * p<.01$. All tests are two-tailed. 
This is an electronic version of an article published in Alcoholism Treatment Quarterly, Jan-Mar 2012, Volume 30, Issue 1, 78-90. Alcoholism Treatment Quarterly is available online at: www.tandfonline.com.

DOI: 10.1080/07347324.2012.635527

Table 2

Within-Person Results for Daytime Variables Predicting Evening Alcohol Use

\begin{tabular}{lccc}
\hline Predictor & $b$ & $S E$ & $t$-value \\
\hline Stress & -0.12 & 0.07 & -1.55 \\
Mood & 0.10 & 0.05 & $2.04^{*}$ \\
Consequences & -0.54 & 0.26 & $-2.03^{*}$ \\
Gender & -1.57 & 0.86 & -1.81 \\
& & & \\
\hline
\end{tabular}

Note. $b=$ pooled unstandardized regression coefficient; SE = standard error.

$* p<.05$. 